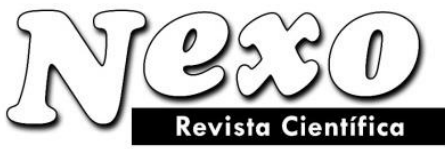

ISSN-E 1995-9516

Universidad Nacional de Ingeniería COPYRIGHT @ (UNI). TODOS LOS DERECHOS RESERVADOS http://revistas.uni.edu.ni/index.php/Nexo https://doi.org/10.5377/nexo.v33i02.10783

\title{
Ranking of units by corrected cross-efficiency method using optimal weights in the smallest interval
}

\section{Clasificación de unidades por el método de eficiencia cruzada corregido usando pesos óptimos en el intervalo más pequeño}

\author{
Fatemeh Gholami Golsefid ${ }^{1}$, Behrouz Daneshian ${ }^{2, *}$, Mohsen Rostamy-Malkhalifeh $^{3}$
}

1 Department of Mathematics, Lahijan Branch, Islamic Azad University, Lahijan, Iran.

2 Department of Mathematics, Central Tehran Branch, Islamic Azad University, Tehran, Iran.

3 Department of Mathematics, Science and Research Branch, Islamic Azad University, Tehran, Iran.

*Corresponding author Email: be_daneshian@yahoo.com

(recibido/received: 03-July-2020; aceptado/accepted: 01-September-2020)

\begin{abstract}
An important method for ranking of decision making units (DMUs) in data envelopment analysis (DEA) is cross-efficiency method. This study proposes a secondary multi-objective model for calculating optimal weights with least dispersion. Firstly, these weights are placed in the smallest interval. Secondly, the cross-efficiency of each of the other units has the least deviation from the CCR efficiency of the same unit. Therefore, optimal weights are obtained which have the least dispersion. As result, the zero optimal weights which lead to the triviality of the relevant index, are avoided as far as possible. Hence, using the average cross-efficiency, the results of the ranking would be more reasonable. Using the proposed model for ranking of six nursing homes, the results show that this model is more accurate. Finally, in order to improve performance of the emergency department of a hospital, the proposed model is used to rank 11 defined scenarios.
\end{abstract}

Keywords: Data envelopment analysis, decision-making units, secondary goals, cross-efficiency, CCR efficiency.

\section{RESUMEN}

Un método importante para clasificar las unidades de toma de decisiones (DMU) en el análisis envolvente de datos (DEA) es el método de eficiencia cruzada. Este estudio propone un modelo secundario multiobjetivo para calcular los pesos óptimos con la menor dispersión. En primer lugar, estos pesos se 
colocan en el intervalo más pequeño. En segundo lugar, la eficiencia cruzada de cada una de las otras unidades tiene la menor desviación de la eficiencia CCR de la misma unidad. Por tanto, se obtienen pesos óptimos que tienen la menor dispersión. Como resultado, se evitan en la medida de lo posible las ponderaciones óptimas cero que conducen a la trivialidad del índice relevante. Por lo tanto, utilizando la eficiencia cruzada promedio, los resultados de la clasificación serían más razonables. Utilizando el modelo propuesto para la clasificación de seis hogares de ancianos, los resultados muestran que este modelo es más preciso. Finalmente, con el fin de mejorar el desempeño del servicio de urgencias de un hospital, se utiliza el modelo propuesto para clasificar 11 escenarios definidos.

Palabras clave: análisis envolvente de datos, unidades de toma de decisiones, metas secundarias, eficiencia cruzada, eficiencia CCR.

\section{INTRODUCTION}

Data envelopment analysis (DEA) is a nonparametric technique for measuring the relative efficiency of decision making units (DMUs). Charnes et al. 1987 first proposed the CCR model to determine the relative efficiency of homogeneous units. Banker et al. 1984 then introduced the BCC model, and later more generalizations were made on these two basic models. Units are divided into two sets of efficient and inefficient DMUs using DEA models. However, the DEA model was unable to differentiate between efficient units; thus, different ranking methods were introduced. The AP model was first proposed by Andersen \&Petersen 1993 for ranking efficient units. The cross-efficiency technique provided by Sexton et al. 1986 is one of the most common ranking methods. The existence of multiple optimal solutions that does not give a unique ranking is the most important problem with this method. The use of secondary goal models is suggested for the elimination of this problem. For example, Doyle et al. 1994 and 1995 introduced the benevolent and aggressive model. Similarly, Liang et al. 2008, 2008a presented another secondary goal model based on the benevolent and aggressive model. In the model, they obtain weights from among the $D M U_{o}$ multiple optimal solutions, where the deviation of units from the ideal efficiency of 1 would be the smallest value, and the unit being evaluated maintains its CCR efficiency. Subsequently, Wang and Chin 2010 improved the model of Laing et al. due to the fact that the ideal efficiency of 1 is unachievable for inefficient units. They introduced another model by replacing CCR efficiency instead of ideal efficiency in the target efficiency. Jahanshahloo et al. 2011 also presented a secondary goal model for cross-efficiency evaluation in which they emphasized the choice of DMU symmetric weights. Jahanshahloo et al. 2013 proposed two models for the ranking of efficient DMUs based on Norm 1 and by using the mean of input/output weights. Moreover, Song et al. 2017 introduced an entropy model for obtaining a set of weights to aggregate cross-efficiency rather than the average cross-efficiency. Carillo et al. 2018 defined a secondary goal that addresses the selection of DEA weights from a neutral perspective. Also Carillo et al. 2018 focused on the aggregation process of cross-efficiency scores and proposed a new approach for deriving meaningful aggregation weights for a more comprehensive evaluation of the units. The present study has proposed a multi-objective model for the calculation of optimal weights. Firstly, these weights are placed in the smallest interval, in which case optimal weights having the least dispersion are obtained. Secondly, the cross-efficiency of each of the other units has the smallest deviation from the CCR efficiency of the same unit. As such, the number of zeros in the optimal weights that lead to the triviality of the relevant index, is minimized. In this way, using the average cross-efficiency would make the ranking more reasonable. The ranking results obtained using the suggested model for an applied example of 6 nursing homes indicate that this model has a more accuracy than other models. Finally, the proposed model is used to rank 11 defined scenarios for the emergency department of a hospital in Jordan, in order to improve its performance. 


\section{CROSS-EFFICIENCY AND SECONDARY GOALS}

Suppose, $x_{i j}$ and $y_{r j}(i=1,2, \ldots, m ; j=1,2, \ldots, n ; r=1,2, \ldots, s)$ are the inputs and outputs of $n$ DMUs. In order to determine the elements of the cross-efficiency matrix, first, the multiple form of the CCR model is used to evaluate the $D M U_{o}(o \in\{1,2, \ldots, n\})$.

$$
\begin{array}{lll}
\max & \theta_{o}=\sum_{r=1}^{s} u_{r} y_{r o} & \\
\text { s.t. } & \sum_{i=1}^{m} v_{i} x_{i o}=1 \\
& \sum_{r=1}^{s} u_{r} y_{r j}-\sum_{i=1}^{m} v_{i} x_{i j} \leq 0 \quad j=1,2, \ldots, n \\
& v_{i} \geq 0 & i=1,2, \ldots, m \\
& u_{r} \geq 0 & r=1,2, \ldots, s
\end{array}
$$

Where $v_{i}$ and $u_{r}$ are $i t h(i=1,2, \ldots, m)$ input and $r$ th $(r=1,2, \ldots, s)$ outputweights. Using the optimal solutions of $u_{r}^{*}$ and $v_{i}^{*}$, the efficiency of $D M U_{o}\left(\theta_{o o}^{*}=\sum_{r=1}^{s} u_{r}^{*} y_{r o}\right)$ and the cross-efficiency of $D M U_{j}\left(\theta_{j o}=\frac{\sum_{r=1}^{s} u_{r}^{*} y_{r j}}{\sum_{i=1}^{m} v_{i}^{*} x_{i j}}\right)$ is obtained. Thereafter, the DMUs are ranked based on the average crossefficiency (Table 1).

Table 1. Cross-efficiency matrix

\begin{tabular}{cccccc}
\hline DMU & 1 & 2 & $\cdots$ & $\mathrm{n}$ & Average Cross Efficiency \\
\hline 1 & $\theta_{11}$ & $\theta_{12}$ & $\cdots$ & $\theta_{1 n}$ & $\frac{1}{n} \sum_{j=1}^{n} \theta_{1 j}$ \\
2 & $\theta_{21}$ & $\theta_{22}$ & $\cdots$ & $\theta_{2 n}$ & $\frac{1}{n} \sum_{j=1}^{n} \theta_{2 j}$ \\
$\vdots$ & $\vdots$ & $\vdots$ & $\cdots$ & $\vdots$ & $\vdots$ \\
$\mathrm{n}$ & $\theta_{n 1}$ & $\theta_{n 2}$ & $\cdots$ & $\theta_{n n}$ & $\frac{1}{n} \sum_{j=1}^{n} \theta_{n j}$ \\
\hline
\end{tabular}

\section{PROPOSED MODEL FOR CALCULATING THE CROSS - EFFICIENCY}

Given that, by using the optimal weights of $D M U_{o}$, the value of cross-efficiency $\operatorname{DMU}_{j}(j=1, \ldots, n)$ is calculated by the equation $\theta_{j o}=\frac{\sum_{r=1}^{s} u_{r}^{*} y_{r j}}{\sum_{i=1}^{m} v_{i}^{*} x_{i j}}$, so we want to obtain the weights with least distribution among the $D M U_{o}$ multiple optimal solutions, so that $\theta_{j o}$ and $\theta_{j j}^{*}$ isare the lowest values. It means that, optimal weights in the smallest interval $[h, z]$ are calculated in a way that, if possible $\theta_{j j}^{*}=\frac{\sum_{r=1}^{S} u_{r}^{*} y_{r j}}{\sum_{i=1}^{m} v_{i}^{*} x_{i j}}$ or in other $\operatorname{words} \sum_{r=1}^{s} u_{r}^{*} y_{r j}-\theta_{j j}^{*} \sum_{i=1}^{m} v_{i}^{*} x_{i j}=0$. But this is not possible in many cases, and given that $\theta_{j j}^{*}$ is the greatest efficiency of $D M U_{j}$, then $\frac{\sum_{r=1}^{S} u_{r}^{*} y_{r j}}{\sum_{i=1}^{m} v_{i}^{*} x_{i j}} \leq \theta_{j j}^{*}$ or in other words $\sum_{r=1}^{S} u_{r}^{*} y_{r j}-\theta_{j j}^{*} \sum_{i=1}^{m} v_{i}^{*} x_{i j} \leq 0$. Therefore, our goal is to calculate the optimal weights at the smallest interval $[h, z]$, whose crossefficiency of $D M U_{j}$ has the least deviation from CCR efficiency of the same unit. As a result, the first goal is to calculate the minimizing of $s_{j}$ in equation $\sum_{r=1}^{s} u_{r}^{*} y_{r j}-\theta_{j j}^{*} \sum_{i=1}^{m} v_{i}^{*} x_{i j}+s_{j}=0$, and the second goal is to calculate the minimizing of $z-h$. In this way, weight distribution is reduced and as a result, a more reasonable ranking is obtained.

With regards to the explanations above, the following multi-objective model is suggested: 


$$
\begin{aligned}
& \min \max _{1 \leq j \leq n}\left\{s_{j}\right\}+z-h \\
& \text { s.t. } \quad \sum_{i=1}^{m} v_{i} x_{i o}=1 \\
& \sum_{r=1}^{s} u_{r} y_{r o}=\theta_{o o}^{*} \\
& \sum_{r=1}^{s} u_{r} y_{r j}-\theta_{j j}^{*} \sum_{i=1}^{m} v_{i} x_{i j}+s_{j}=0 \quad \forall j \\
& h \leq v_{i} \leq z \quad \forall i \\
& h \leq u_{r} \leq z \quad \forall r \\
& s_{j}, u_{r}, v_{i} \geq 0 \quad \forall r, i, j \\
& h, z \geq 0
\end{aligned}
$$

Theorem 1. Model (2) is possible.

Proof. Given that model (1) is possible, it is assumed that $\left(u_{r}^{*}, v_{i}^{*}, \theta_{o}^{*}\right)$ is an optimal solution of model (1), and it has been shown that this solution is also possible for model (2).

Since $\left(u_{r}^{*}, v_{i}^{*}, \theta_{o}^{*}\right)$ is an optimal solution of model (1), it therefore satisfies constraints (2.1) and (2.2). On the other hand, by placing $h=\min \left\{v_{i}^{*}, u_{r}^{*}(\forall i, r)\right\}$ and $z=\max \left\{v_{i}^{*}, u_{r}^{*}(\forall i, r)\right\}$, this solution also satisfies in constraints (2.4) and (2.5).

Given that $\theta_{j j}^{*}\left(\right.$ for $\left.\forall_{\mathrm{j}}\right)$ is the greatest efficiency of $D M U_{j}$, then:

$\frac{\sum_{r=1}^{s} u_{r}^{*} y_{r j}}{\sum_{i=1}^{m} v_{i}^{*} x_{i j}} \leq \theta_{j j}^{*} \Rightarrow \sum_{r=1}^{S} u_{r}^{*} y_{r j}-\theta_{j j}^{*} \sum_{i=1}^{m} v_{i}^{*} x_{i j} \leq 0 \Rightarrow \sum_{r=1}^{s} u_{r}^{*} y_{r j}-\theta_{j j}^{*} \sum_{i=1}^{m} v_{i}^{*} x_{i j}+s_{j}=0$

Therefore, this solution also satisfies in constraint (2.3). As a result, $\left(u_{r}^{*}, v_{i}^{*}, \theta_{o}^{*}\right)$ is a possible solution of model (2).

Considering $\delta=\max _{1 \leq j \leq n}\left\{s_{j}\right\}$, the nonlinear model (2) was converted to the following linear model:

$$
\begin{array}{lll}
\min & \delta+z-h & \\
\text { s.t. } & \delta \geq s_{j} & \\
& \sum_{i=1}^{m} v_{i} x_{i o}=1 & \\
& \sum_{r=1}^{s} u_{r} y_{r o}=\theta_{o o}^{*} & \\
& \sum_{r=1}^{s} u_{r} y_{r j}-\theta_{j j}^{*} \sum_{i=1}^{m} v_{i} x_{i j}+s_{j}=0 \quad \forall j \\
& h \leq v_{i} \leq z & \forall i \\
& h \leq u_{r} \leq z & \forall r \\
& s_{j}, u_{r}, v_{i} \geq 0 & \forall r, i, j \\
& h, z \geq 0 &
\end{array}
$$

Now, using an applied example, it has been shown that model (3) ranks units with a higher accuracy.

\section{NUMERICAL EXAMPLE}

Example 1. Table 2 includes data on six nursing homes with two inputs and two outputs (Sexton et al., 1986), and their CCR efficiency.

$x_{1}$ : Staff Hours per day (including nurses, physicians, etc.)

$x_{2}$ : Suppliers (equipment) per day (measured in 1000 of dollars)

$y_{1}$ : Total medical care- reimbursed patient days

$y_{2}$ : Total privately- paid patient days 
Table 2. Input and output data of nursing homes and CCR efficiency

\begin{tabular}{cccccc}
\hline DMU & $x_{1}$ & $x_{2}$ & $y_{1}$ & $y_{2}$ & CCR efficiency \\
\hline 1 & 1.50 & 0.20 & 1.40 & 0.35 & 1.0000 \\
2 & 4.00 & 0.70 & 1.40 & 2.10 & 1.0000 \\
3 & 3.20 & 1.20 & 4.20 & 1.05 & 1.0000 \\
4 & 5.20 & 2.00 & 2.80 & 4.20 & 1.0000 \\
5 & 3.50 & 1.20 & 1.90 & 2.50 & 0.9775 \\
6 & 3.20 & 0.70 & 1.40 & 1.50 & 0.8675 \\
\hline
\end{tabular}

Fuente: (Sexton et al., 1986)

The ranking results and optimal weight of units by cross-efficiency method using model (1) are presented in Tables 3 and 4, respectively.

Table 3. Cross-efficiency matrix and ranking of units using model (1)

\begin{tabular}{ccccccccc}
\hline & $\mathrm{DMU}_{1}$ & $\mathrm{DMU}_{2}$ & $\mathrm{DMU}_{3}$ & $\mathrm{DMU}_{4}$ & $\mathrm{DMU}_{5}$ & $\mathrm{DMU}_{6}$ & Average & Rank \\
\hline $\mathrm{DMU}_{1}$ & 1.0000 & 1.0000 & 1.0000 & 0.7111 & 1.0000 & 1.0000 & 0.9519 & 1 \\
$\mathrm{DMU}_{2}$ & 1.0000 & 1.0000 & 0.8640 & 0.6500 & 1.0000 & 1.0000 & 0.9190 & 2 \\
$\mathrm{DMU}_{3}$ & 0.5000 & 0.5000 & 1.0000 & 1.0000 & 0.9285 & 0.9285 & 0.8095 & 5 \\
$\mathrm{DMU}_{4}$ & 0.7000 & 0.7000 & 1.0000 & 1.0000 & 1.0000 & 1.0000 & 0.9000 & 3 \\
$\mathrm{DMU}_{5}$ & 0.7083 & 0.7083 & 0.9676 & 0.9205 & 0.9775 & 0.9775 & 0.8766 & 4 \\
$\mathrm{DMU}_{6}$ & 0.7551 & 0.7551 & 0.8046 & 0.6482 & 0.8675 & 0.8675 & 0.7830 & 6 \\
\hline
\end{tabular}

Table 4. Optimal weights in cross-efficiency method (1)

\begin{tabular}{lcccc}
\hline & $u_{1}$ & $u_{2}$ & $v_{1}$ & $v_{2}$ \\
\hline $\mathrm{DMU}_{1}$ & 0.0357 & 0.0143 & 0 & 5 \\
$\mathrm{DMU}_{2}$ & 0.0102 & 0.0041 & 0 & 1.4286 \\
$\mathrm{DMU}_{3}$ & 0.0168 & 0.0028 & 0.1724 & 0.3736 \\
$\mathrm{DMU}_{4}$ & 0.0104 & 0.0017 & 0.1923 & 0 \\
$\mathrm{DMU}_{5}$ & 0.0115 & 0.0030 & 0.1099 & 0.5128 \\
$\mathrm{DMU}_{6}$ & 0.0162 & 0.0043 & 0.1546 & 0.7216 \\
\hline
\end{tabular}

It is seen from Table 4 that using cross-efficiency method, the optimal weights of the first input of efficient units $\mathrm{DMU}_{1}$ and $D M U_{2}$ and the second input of efficient unit $D M U_{4}$ are zero. That means that the desired inputs are ignored in the evaluation of these units as well as in the calculation of cross-efficiency. This makes the cross-efficiency and reasonable ranking not to be achieved. For the second input weight, $D M U_{1}$ the value of 5 is obtained, which is very large in comparison to all other weights. In other words, the dispersion of optimal weights is between zero and 5. Meanwhile, these efficient units have other optimal weights that can create better conditions. 
After applying model (3), the ranking of units with this model is shown in Table 5 and optimal weights as well as their boundaries are displayed in Table 6.

Table 5. Cross-efficiency matrix and ranking of units using model (3)

\begin{tabular}{lllllllll}
\hline & $\mathrm{DMU}_{1}$ & $\mathrm{DMU}_{2}$ & $\mathrm{DMU}_{3}$ & $\mathrm{DMU}_{4}$ & $\mathrm{DMU}_{5}$ & $\mathrm{DMU}_{6}$ & Average & Rank \\
\hline $\mathrm{DMU}_{1}$ & 1.0000 & 1.0000 & 0.8627 & 0.6471 & 1.0000 & 1.0000 & 0.9183 & 3 \\
$\mathrm{DMU}_{2}$ & 0.8640 & 1.0000 & 0.7660 & 0.7660 & 1.0000 & 1.0000 & 0.8993 & 4 \\
$\mathrm{DMU}_{3}$ & 1.0000 & 0.8295 & 1.0000 & 0.7500 & 0.8295 & 0.8295 & 0.8731 & 5 \\
$\mathrm{DMU}_{4}$ & 1.0000 & 1.0000 & 1.0000 & 1.0000 & 1.0000 & 1.0000 & 1.0000 & 1 \\
$\mathrm{DMU}_{5}$ & 0.9676 & 0.9775 & 0.9487 & 0.9331 & 0.9775 & 0.9775 & 0.9636 & 2 \\
$\mathrm{DMU}_{6}$ & 0.8046 & 0.8675 & 0.7355 & 0.7033 & 0.8675 & 0.8675 & 0.8076 & 6 \\
\hline
\end{tabular}

Table 6. Optimal weights and their upper and lower boundaries using model (3)

\begin{tabular}{lcccccc}
\hline & $u_{1}$ & $u_{2}$ & $v_{1}$ & $v_{2}$ & $h$ & $z$ \\
\hline $\mathrm{DMU}_{1}$ & 0.0505 & 0.0084 & 0.5172 & 1.1207 & 0.0084 & 1.1207 \\
$\mathrm{DMU}_{2}$ & 0.0045 & 0.0045 & 0.1376 & 0.6422 & 0.0045 & 0.6422 \\
$\mathrm{DMU}_{3}$ & 0.0169 & 0.0028 & 0.2273 & 0.2273 & 0.0028 & 0.2273 \\
$\mathrm{DMU}_{4}$ & 0.0022 & 0.0022 & 0.1389 & 0.1389 & 0.0022 & 0.1389 \\
$\mathrm{DMU}_{5}$ & 0.0115 & 0.0030 & 0.1099 & 0.5128 & 0.0030 & 0.5128 \\
$\mathrm{DMU}_{6}$ & 0.0162 & 0.0043 & 0.1546 & 0.7216 & 0.0043 & 0.7216 \\
\hline
\end{tabular}

The fact that the optimal weights of the first input of efficient units $D M U_{1}$ and $D M U_{2}$ and the second input of efficient unit $D M U_{4}$ using model (1) become zero and it means ignoring the desired inputs in the evaluation of the units as well as calculating cross-efficiency. These units also have non-zero optimal weights, which can generate a reasonable result. From the results presented in Table 6, by using model (3), with the aim of calculating the optimal weights with the least dispersion, non-zero weights were obtained from among the multiple optimal solutions of these units. The dispersion of these weights is much lower compared to the previous method. Consequently, using these non-zero weights, we get a more reasonable ranking. The results show that the proposed model is more accurate than other models.

Now, model (3) is applied to improve the performance of a service system.

Example 2. In order to improve the performance of the emergency department of a hospital in Jordan, AlRefaie et al. 2014 first simulated this department. Thereafter, they defined and simulated several different scenarios for changing the tasks of nurses. Subsequently, using simulation results, each scenario was considered as a DMU and the results were considered as inputs and outputs of that unit. Then, using the aggressive model, they evaluated and ranked the scenarios. Here, the proposed model is used to rank those scenarios and introduce the best scenario. Table 7 shows the inputs and outputs of DMUs and the CCR efficiency. The inputs and outputs are:

$x_{1}$ : Number of nurses

$x_{2}$ : Average time in system

$y_{1}$ : Nurse's utilization

$y_{2}$ : Number of served patients 
Table 7. Input and outputs of 11 DMUs (simulated scenarios) and their efficiency

\begin{tabular}{cccccc}
\hline & $\mathrm{X}_{1}$ & $\mathrm{X}_{2}$ & $\mathrm{Y}_{1}$ & $\mathrm{Y}_{2}$ & CCR efficiency \\
\hline$D M U_{1}$ & 6 & 195.2 & 52.21 & 8853.5 & 0.959868 \\
$D M U_{2}$ & 6 & 71.05 & 51.23 & 8298 & 1 \\
$D M U_{3}$ & 6 & 259.74 & 61.55 & 8818 & 0.925654 \\
$D M U_{4}$ & 6 & 183.24 & 61.61 & 8934 & 1 \\
$D M U_{5}$ & 6 & 1401.76 & 52.02 & 8307 & 0.777285 \\
$D M U_{6}$ & 6 & 237.61 & 52.15 & 8981 & 0.941417 \\
$D M U_{7}$ & 7 & 72.51 & 44.3 & 8932 & 0.973626 \\
$D M U_{8}$ & 6 & 218.27 & 51.59 & 8856 & 0.942561 \\
$D M U_{9}$ & 7 & 70.27 & 43.74 & 8814 & 0.972359 \\
$D M U_{10}$ & 5 & 326.24 & 62.42 & 8906 & 1 \\
$D M U_{11}$ & 7 & 64.71 & 43.67 & 8793 & 1 \\
\hline Fuente: (Refaie et al., 2014) & & & & &
\end{tabular}

$\mathrm{DMU}_{1}$ is the current scenario of the system and other DMUs are defined scenarios for the system. By applying model (3), the cross-efficiency was calculated, and then the units were ranked by average crossefficiency. The results are presented in Table 8.

Table 8. Results and rankings of 11 DMUs (simulated scenarios) using model (3)

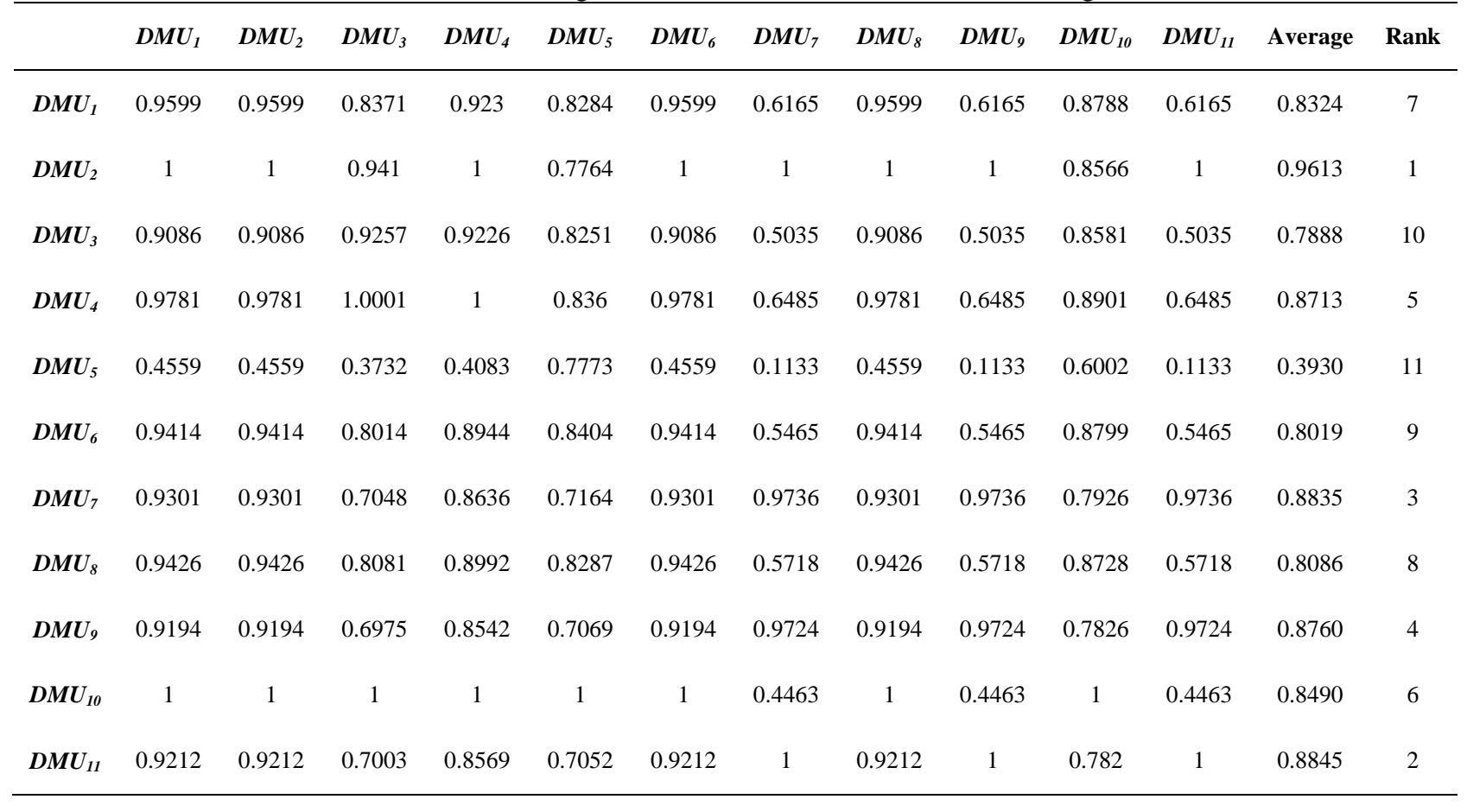

The results in Table 8 show that scenario 2 is chosen as the best scenario with an efficiency of 0.9613 compared to the current scenario with an efficiency of 0.8324 , which is $15 \%$ more efficient. Therefore, this scenario was introduced to change nurses' duties in order to improve system performance. 


\section{CONCLUSION}

Although different approaches have been used to rank efficient units in DEA models, however, almost all of these approaches are not able to rank non-extreme efficient DMUs. The cross-efficiency method is a way to rank all DMUs, nevertheless, secondary goal models are used because of the possibility of multiple optimal solution which lead to different rankings. A multi-objective model was proposed for calculating optimal weights in this paper. First, these weights are placed in the smallest interval, and second, crossefficiency of each of the other units has the least deviation from the same CCR efficiency. Consequently, optimal weights are obtained with the least dispersion and also, the number of zeros in the optimal weights that lead to the triviality of the relevant index, is minimized. Therefore, ranking by average crossefficiency is more reasonable this way. The results of the ranking achieved with the proposed model, for an applied example of 6 nursing homes, indicate that this model is more accurate than other models. This is because it prevents the weights of units which have multiple optimal solution from becoming zero, and obtains optimal weights with the least dispersion. Finally, the proposed model was used to rank 11 scenarios of the emergency department of a hospital in Jordan. The results showed that the efficiency increased by $15 \%$, when this method was used to rank the scenarios, when the system scenario is changed.

\section{REFERENCES}

Al-Refaie, A., Fouad, R. H., Li, M. H., \& Shurrab, M. (2014). Applying simulation and DEA to improve performance of emergency department in a Jordanian hospital. Simulation Modelling Practice and Theory, 41, 59-72.

Andersen, P., \& Petersen, N. C. (1993). A procedure for ranking efficient units in data envelopment analysis. Management science, 39(10), 1261-1264.

Banker, R. D., Charnes, A., \& Cooper, W. W. (1984). Some models for estimating technical and scale inefficiencies in data envelopment analysis. Management science, 30(9), 1078-1092.

Carrillo, M., \& Jorge, J. M. (2018). An alternative neutral approach for cross-efficiency evaluation. Computers \& Industrial Engineering, 120, 137-145.

Carrillo, M., \& Jorge, J. M. (2018). Integrated approach for computing aggregation weights in cross-efficiency evaluation. Operations Research Perspectives, 5, 256-264.

Charnes, A., Cooper, W. W., \& Rhodes, E. (1978). Measuring the efficiency of decision making units. European journal of operational research, 2(6), 429-444.

Doyle, J., \& Green, R. (1994). Efficiency and cross-efficiency in DEA: Derivations, meanings and uses. Journal of the operational research society, 45(5), 567-578.

Doyle, J. R., \& Green, R. H. (1995). Cross-Evaluation In Dea: Improving Discrimination Among Dmus. INFOR: Information Systems and Operational Research, 33(3), 205-222.

Jahanshahloo, G. R., \& Shahmirzadi, P. F. (2013). New methods for ranking decision making units based on the dispersion of weights and Norm 1 in Data Envelopment Analysis. Computers \& Industrial Engineering, 65(2), 187-193.

Jahanshahloo, G. R., Lotfi, F. H., Jafari, Y., \& Maddahi, R. (2011). Selecting symmetric weights as a secondary goal in DEA cross-efficiency evaluation. Applied Mathematical Modelling, 35(1), 544-549.

Liang, L., Wu, J., Cook, W. D., \& Zhu, J. (2008). Alternative secondary goals in DEA cross-efficiency evaluation. International Journal of Production Economics, 113(2), 1025-1030.

Liang, L., Wu, J., Cook, W. D., \& Zhu, J. (2008a). The DEA game cross-efficiency model and its Nash equilibrium. Operations research, 56(5), 1278-1288.

Sexton, T. R., Silkman, R. H., \& Hogan, A. J. (1986). Data envelopment analysis: Critique and extensions. New Directions for Program Evaluation, 1986(32), 73-105.

Song, M., Zhu, Q., Peng, J., \& Gonzalez, E. D. S. (2017). Improving the evaluation of cross efficiencies: A method based on Shannon entropy weight. Computers \& Industrial Engineering, 112, 99-106.

Wang, Y. M., \& Chin, K. S. (2010). Some alternative models for DEA cross-efficiency evaluation. International Journal of Production Economics, 128(1), 332-338. 